\title{
Recommendations for Benchmarking Web Site Usage among Academic Libraries
}

\author{
Christy Hightower, Julie Sih, and Adam Tilghman
}

\begin{abstract}
The Web sites that academic libraries are developing for their research communities represent an important new aspect of information management. Comparative statistical analysis of Web site usage among similar institutions would improve librarians' ability to evaluate the effectiveness of their efforts. A centralized voluntary reporting structure for Web server usage statistics, coordinated by the Association of Research Libraries' (ARL's) Office of Statistics, would provide a significant service to academic librarians. Factors to consider in designing such a benchmarking program are discussed, based on a pilot study of Web site usage statistics from fourteen science and technology libraries.
\end{abstract}

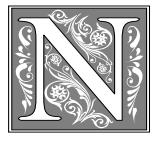

ew measures of library activity attract the attention of practitioners and administrators alike because they promise answers to two eternal questions: (1) How effectively are librarians meeting the information needs of their primary clientele? and (2) Have their own approaches to budgetary and technological challenges been more or less successful than those of comparable institutions?

As we progress toward the largely digital library of the future, the active role of librarians in designing user interfaces and expert systems further whets their already voracious appetite for usage data. The foundation for many institutions' digital library efforts is their development of highly customized Web sites. This is fortuitous because Web servers automati- cally log data about the demand for specific resources within these sites.

One expects to find copious professional literature on how academic libraries can capitalize on readily available data on the size and characteristics of their own Web site audiences. After all, the popular press has seen fit to devote lengthy articles to the scores of tools and services available for Web server log analysis, as have trade journals in the fields of business and computing. Therefore, it is astonishing to discover how little the library and information science journals have published about the potential of these statistics as a measure of library activity.

This dearth of literature has left librarians ill-informed as to the capabilities of Web server log analysis software. Many

Christy Hightower is the Web Coordinator in the Science $\mathcal{E}$ Engineering Library at the University of California-San Diego; e-mail: chightow@ucsd.edu. Julie Sih is formerly the Corporate Programs Librarian at the University of California-San Diego; e-mail: jsih@gort.ucsd.edu. Adam Tilghman is the Web Programmer Analyst in the Science Libraries at the University of California-San Diego; e-mail: agt@ucsd.edu. 


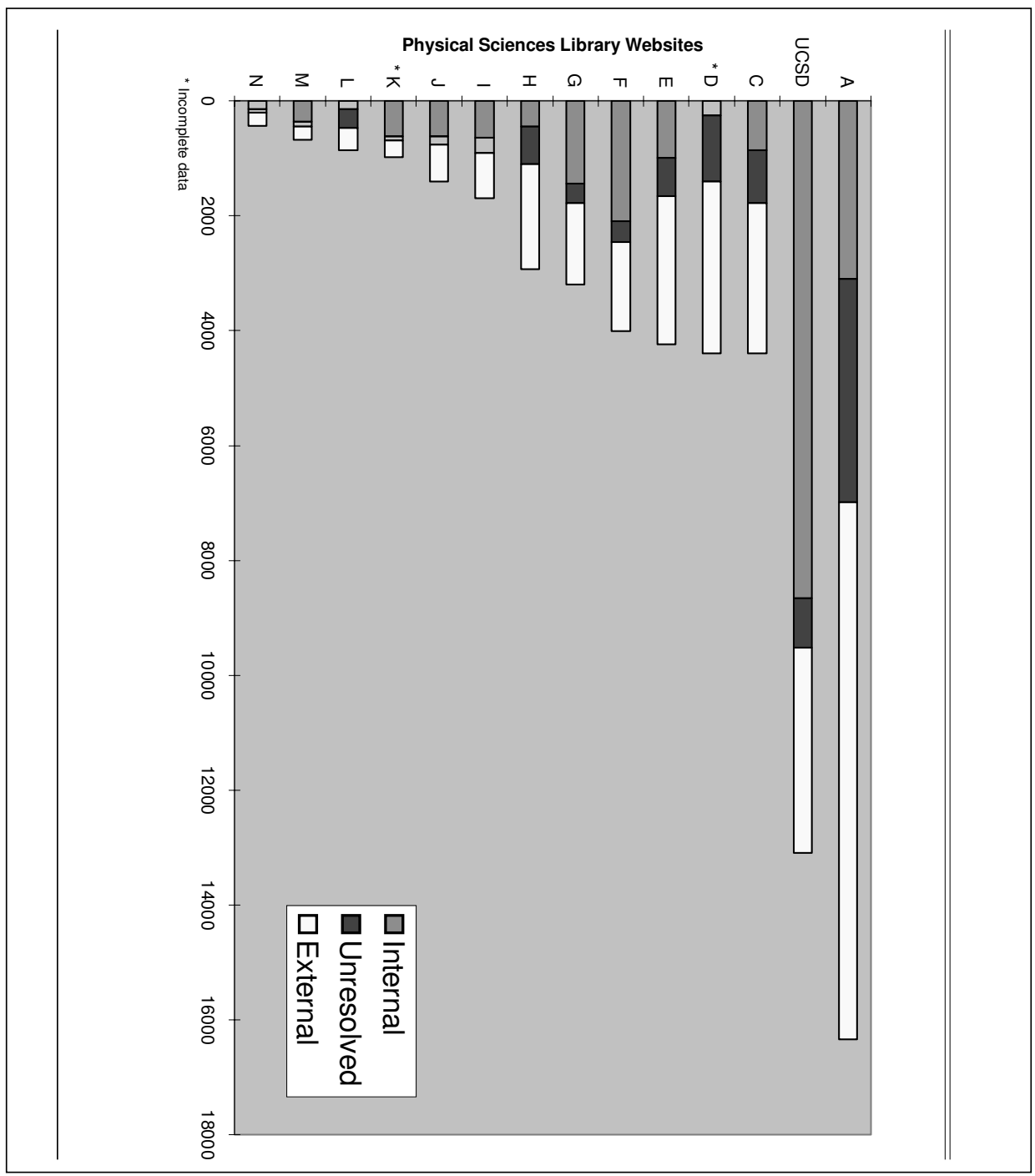

academic libraries undervalue, or even ignore, their Web traffic data. Even libraries that regularly analyze their server logs have difficulty interpreting the results in the absence of benchmarks. Without external comparisons, judging the success of a site is difficult because the size of the potential audience is unknown. Fourteen thousand page requests per month may sound impressive, but how does one know whether that indicates stellar or abysmal demand for a midsize university's sci/tech library Web site?
To help library directors and Web developers make sense of their own Web site traffic measurements, the authors of this article examine how a benchmarking program might be developed to compare the statistics of one academic library Web site against those of others. In so doing, the authors identify several practical and philosophical issues concerning intercampus comparisons of library Web site traffic. Because such Web sites are unique resources developed for specific audiences, meaningful benchmarking can oc- 


\begin{tabular}{|c|c|c|c|c|c|c|}
\hline \multicolumn{7}{|c|}{$\begin{array}{c}\text { TABLE } 1 \\
\text { Page Requests by Site versus Selected Pages (Feb. 1996) }\end{array}$} \\
\hline \multirow{2}{*}{$\begin{array}{l}\text { Physical } \\
\text { Sciences Library } \\
\text { Web Sites } \\
\end{array}$} & \multicolumn{2}{|c|}{ Total Site } & \multicolumn{2}{|c|}{ Top Ten Pages } & \multicolumn{2}{|c|}{$\begin{array}{l}\text { Engineering Web } \\
\text { Resources Pages }\end{array}$} \\
\hline & Requests & Rank & Requests & Rank & Requests & Rank \\
\hline A & 16,339 & 1 & 15,951 & 1 & 4,956 & 1 \\
\hline UCSD & 13,086 & 2 & 8,698 & 2 & 512 & 2 \\
\hline $\mathrm{C}$ & 4,394 & 3.5 & 4,340 & 3 & $\mathrm{n} / \mathrm{a}$ & $\mathrm{n} / \mathrm{a}$ \\
\hline $\mathrm{D}^{2}$ & 4,390 & 3.5 & 2,712 & 5 & 218 & 6 \\
\hline $\mathrm{E}$ & 4,241 & 5 & 2,408 & 6 & 88 & 9 \\
\hline $\mathrm{F}$ & 4,001 & 6 & 3,684 & 4 & 294 & 4 \\
\hline $\mathrm{G}$ & 3,189 & 7 & 1,886 & 7 & 222 & 5 \\
\hline $\mathrm{H}$ & 2,927 & 8 & 1,514 & 9 & 155 & 8 \\
\hline I & 1,694 & 9 & 1,694 & 8 & $\mathrm{n} / \mathrm{a}$ & $\mathrm{n} / \mathrm{a}$ \\
\hline $\mathrm{J}$ & 1,395 & 10 & 1,131 & 10 & 157 & 7 \\
\hline $\mathrm{K}^{2}$ & 1,081 & 11 & 610 & 13 & 46 & 10 \\
\hline $\mathrm{L}$ & 851 & 12 & 785 & 11 & 16 & 12 \\
\hline M & 679 & 13 & 679 & 12 & 360 & 3 \\
\hline $\mathrm{N}$ & 429 & 14 & 329 & 14 & 27 & 11 \\
\hline $\begin{array}{ll}1 & \text { Includes only th } \\
2 & \text { Incomplete data }\end{array}$ & $\begin{array}{l}\text { ses with exte } \\
\text { le }\end{array}$ & al links & & & & \\
\hline
\end{tabular}

cur only among carefully selected peers whose Web sites share essential characteristics. Moreover, equitable comparisons require uniform definition of measurement units, as well as establishment of a standardized approach to collection, analysis, and reporting.

Based on their experience analyzing the Web server log files of fourteen universities' science and engineering libraries, as well as their evaluation of standards proposed by two Internet advertising bodies, the authors propose voluntary guidelines and a common set of metrics for estimation of library Web site audiences. They also assert that the ARL might provide a valuable service to its member institutions by facilitating this standardization process and providing a mechanism whereby academic libraries can choose appropriate peers and models.

\section{Methodology}

With no relevant research models in library and information science journals, the authors' main sources of technical in- formation were the Web site of the wwwstat 2.0 analysis software, ${ }^{1}$ the FAQ (frequently asked questions) document for the comp.infosystems.www USENET newsgroups, ${ }^{2}$ and anecdotal advice shared in forums such as the Web4Lib electronic discussion list. ${ }^{3}$ The authors
Because such Web sites are unique resources developed for specific audiences, meaningful benchmarking can occur only among carefully selected peers whose Web sites share essential characteristics.

also consulted several business and computing articles whose reports of known problems with Web site audience estimation helped in planning their approach. ${ }^{4}$

The authors began their study in November of 1995 by identifying possible peers for the Science \& Engineering (S\&E) Library at the University of CaliforniaSan Diego (UCSD). They invited partici- 


\begin{tabular}{|c|c|c|c|c|}
\hline \multicolumn{5}{|c|}{$\begin{array}{c}\text { TABLE } 2 \\
\text { Total Page Requests versus Edited }{ }^{1} \text { Byte Totals } \\
\text { (Feb. 1996) }\end{array}$} \\
\hline \multirow{2}{*}{$\begin{array}{l}\text { Physical } \\
\text { Sciences Library } \\
\text { Web Sites }\end{array}$} & \multicolumn{2}{|c|}{ Total } & \multicolumn{2}{|c|}{ Total } \\
\hline & Requests & Rank & Kilobytes & Rank \\
\hline A & 16,339 & 1 & 70,610 & 2 \\
\hline UCSD & 13,086 & 2 & 74,346 & 1 \\
\hline $\mathrm{C}$ & 4,394 & 3.5 & 60,932 & 3 \\
\hline $\mathrm{D}^{2}$ & 4,390 & 3.5 & 40,007 & 4 \\
\hline $\mathrm{E}$ & 4,241 & 5 & 763 & 14 \\
\hline $\mathrm{F}$ & 4,001 & 6 & 16,050 & 6 \\
\hline $\mathrm{G}$ & 3,189 & 7 & 19,938 & 5 \\
\hline $\mathrm{H}$ & 2,927 & 8 & 10,349 & 7 \\
\hline I & 1,694 & 9 & 4,548 & 11 \\
\hline $\mathrm{J}$ & 1,395 & 10 & 8,490 & 9 \\
\hline $\mathrm{K}^{2}$ & 1,081 & 11 & 4,380 & 12 \\
\hline $\mathrm{L}$ & 851 & 12 & 2,038 & 13 \\
\hline $\mathrm{M}$ & 679 & 13 & 8,724 & 8 \\
\hline $\mathrm{N}$ & 429 & 14 & 5,201 & 10 \\
\hline
\end{tabular}

ticipants based on the data collected. Rather, the study's aim was to gain valuable experience in the process of benchmarking in order to make informed recommendations on what data to measure and how best to collect and analyze those data for benchmarking in the library setting. The rankings presented in figure 1 and tables 1 and 2 are for purposes of comparing the metrics used, not the institutions. The authors felt that a small sample size was sufficient to accomplish these objectives and were not overly concerned when institutions with multiple Web servers were able to provide data for only a single server. Other aspects of the methodology used, which are identified below,

pation from the sci/tech libraries of the following institutions: sister University of California campuses, the eight institutions used by the University of California for other benchmarking purposes (e.g., faculty salary comparisons), and some additional universities noted for their sci/tech programs. Of the twenty ARL and non-ARL institutions invited to participate, fourteen (including UCSD) participated fully by supplying their sci/tech libraries' raw Web server log files for the month of February 1996. The participating library institutions were: the University of California campuses at Berkeley, Davis, Irvine, Riverside, San Diego, Santa Barbara, and Santa Cruz; Cornell University; the Massachusetts Institute of Technology; Stanford University's Engineering Library; the State University of New York at Buffalo; the University of Illinois at Urbana-Champaign; the University of Michigan; and the University of Southern California.

It was not the authors' intent to assign relative performance outcomes to the par- also reflect the pilot nature of the authors' efforts.

Most participants made their raw February 1996 Web server access log files available by assigning them a uniform resource locator (URL) and allowing the authors to grab the data through their Web browsers, although two institutions sent their files via file transfer protocol (FTP). After obtaining the log files, the authors isolated the data for the specific Web pages they were interested in before running the files through analysis software (wwwstat 2.0).

\section{Why Raw Log Files Were Requested}

As they currently exist, Web server statistics are based on the data contained in a server's access log files. Each request for a document from a site is recorded as a line in that Web server's log (see figure 2). Most servers support the common log file format (CLF), which keeps very simple request information. It contains the visitor's host name (the machine 
name or IP address), the date and time of the request, the URL of the page being requested, the number of bytes transferred, and some technical information about the hypertext transfer protocol (HTTP) request itself (for instance, how successful the request was). Because each line rep- resents a single hit or request, hit counts for each file requested are obtained by adding up the number of lines of data in the log containing the URL for that file.

Obtaining participants' raw log files enabled the authors to use the same analysis software, configured in the same way, on each sample. It also allowed them to determine which Web pages on each site would be included or ignored. This degree of standardization is vital for benchmarking purposes.

\section{Challenges of Performing Analysis on the Raw Log Files}

Although the raw data approach offered the greatest level of standardization for the study, it also posed a number of problems. First, it provided only a very brief window of opportunity in which to obtain the files because some institutions' server software was configured to purge or overwrite their log files automatically at the stroke of midnight on the final day of the month. Second, because the raw data files were very large (some as large as 99.9 megabytes for a single month), their transmission over slow connections took much longer than expected. Finally, upon arrival at the authors' site, they consumed significant amounts of disc storage space (not to mention computer processing time for analysis). The authors also discovered that some of these massive files were not compliant with CLF format standards, so addi- 
tional programming time was needed to convert the files into a format acceptable to the wwwstat analysis software.

In the interests of standardization, the authors eliminated multimedia files and error messages from their comparisons. Fortunately, the wwwstat software may be instructed to do this automatically; however, to be certain that only the traf-

\section{In the interests of standardization, the authors eliminated multimedia files and error messages from their comparisons.}

fic of sci/tech library pages on each server was considered, the authors were forced to visit each site individually and work their way through every link to identify potentially "relevant" pages. This list was then verified with the Web site creators to ensure that important Web pages had not been overlooked. (To avoid having these visits reflected in the February 1996 $\log$ files, this verification was performed in late January 1996.)

\section{Selecting Pages for Analysis}

One of this approach's most important and time-consuming steps proved to be the identification and isolation of the files relevant to the study before performing statistical analysis. Access logs are designed to record requests for all files on a particular server; thus, in most cases, hits on Web documents irrelevant to the study were recorded faithfully alongside hits on the Web pages of interest.

The selection of pages for analysis involved some difficult and subjective decisions. For example, the UCSD S\&E Library manages a single Web site covering the physical sciences, mathematics, and engineering disciplines, but many traditional peer institutions divide these disciplines among multiple branch libraries, usually with a separate Web site for each administrative unit (see figure 3). In an effort to make equitable comparisons with the UCSD S\&E Library Web site, the authors attempted to construct virtual peers by combining statistics from multiple sci/tech library Web sites at the same institution, whenever appropriate and possible, and excluded hits on Web pages devoted to disciplines not covered by the S\&E Library. However, it was impossible to obtain log files from all the Web servers the authors would like to have included in the study, and it is reasonable to expect that institutions $\mathrm{D}$ and $\mathrm{K}$ in table 1 would have had higher page request totals had the authors been able to obtain data for all of those institutions' relevant libraries.

Because the final report was highly customized to the authors' own institution's benchmarking goals, the results were decidedly less useful for the other participants. For these other institutions to reap the same level of benefits under this model, each would need to obtain the raw data and perform an analysis based on its own Web page selection criteria. Most participants would find this prohibitively labor-intensive for groups of more than two or three institutions. Therefore, for large-scale benchmarking efforts, the authors advocate a model that would eliminate duplication of analysis efforts by providing a more objective assessment of all participating institutions' relative performance across the board. Further recommendations and practical advice for such a program are outlined below.

\section{Additional Background}

Since the authors' initial literature review, there have been few significant contributions to the literature. Notable monographs are Rick Stout's Web Site Stats: Tracking Hits and Analyzing Traffic and Robert W. Buchanan and Charles Lukaszewski's Measuring the Impact of Your Web Site, both of which contain tutorial-level technical advice. ${ }^{5}$ Among the critiques of selected log analysis software products and services ${ }^{6}$ is Tova Stabin and Irene Owen's case study “Gathering Us- 


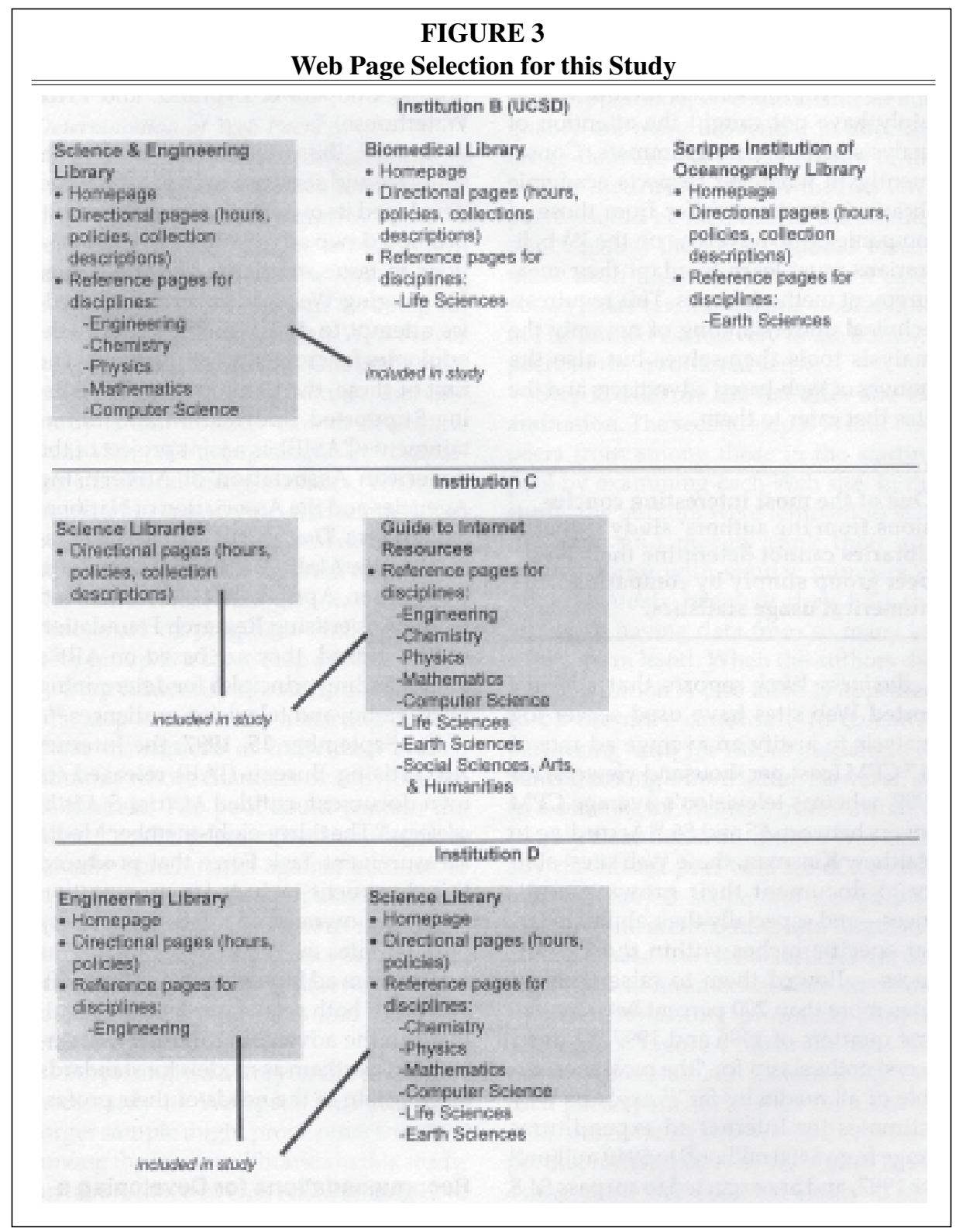

age Statistics at an Environmental Health Library Web Site," which compares three freeware analysis tools' performance on the same server log file. ${ }^{7}$ Another libraryoriented study is Norman Friesen's "Monitoring the Use of World Wide Web Pages," which provides a comprehensive literature review for online usage mea- surements. ${ }^{8}$ All the above discuss how to analyze a single server log. As of October 1997, there had been no cross-site comparative studies. $^{9}$

It is advertisers who are hammering out Web measurement standards and guidelines and who are striving to push the technology beyond what it is capable 
of today. Librarians' needs in terms of Web usage data, scarcely articulated even in our own professional literature, certainly have not caught the attention of analysis software programmers. Consequently, in whatever respects academic libraries' situations differ from those of companies who advertise on the Web, librarians must learn to adapt their measurement methodologies. This requires a technical understanding of not only the analysis tools themselves but also the motives of Web-based advertisers and the sites that cater to them.

\section{One of the most interesting conclu- sions from the authors' study is that libraries cannot determine their Web peer group simply by comparing numerical usage statistics.}

Business Week reports that ad-supported Web sites have used server log analysis to justify an average ad rate of $\$ 17$ CPM (cost per thousand viewers) for 1997, whereas television's average CPM hovers between $\$ 5$ and $\$ 6 .{ }^{10}$ According to Matthew Kinsman, these Web sites' ability to document their growing audiences-and especially their ability to target specific niches within those audiences-allowed them to raise their ad rates more than 200 percent between the first quarters of 1996 and 1997.11 Advertisers' enthusiasm for "the most measurable of all media by far"12 explains why estimates for Internet ad expenditures range from $\$ 400$ million $^{13}$ to $\$ 940$ million $^{14}$ for 1997, and are expected to surpass $\$ 4.8$ billion by the year $2000 .^{15}$

Advertisers' well-publicized doubts about the reliability of Web server statistics have spawned scores of companies offering independent, third-party measurements and/or auditing. ${ }^{16}$ These include ventures of such newsworthy companies as Nielsen Media Research; magazine trackers ABC (Audit Bureau of Circulation) and BPA (Business Publications Audit) International; and the so-called Big
Three of financial accounting (Ernst \& Young, Coopers \& Lybrand, and Price Waterhouse). ${ }^{17}$

In 1997, the proliferation of analysis software and services, each of which had developed its own units of measurement, prompted two advertising trade associations to issue standards and guidelines for gauging Web audiences. ${ }^{18}$ Both bodies attempt to define metrics and methodologies for cross-site comparisons. The first of these, the Coalition for Advertising-Supported Information and Entertainment (CASIE), is a joint project of the American Association of Advertising Agencies and the Association of National Advertisers. The CASIE Guiding Principles of Interactive Media Audience Measurements, released on April 3, 1997, are endorsed by the Advertising Research Foundation (ARF); indeed, they are based on ARF's long-standing principles for determining print, radio, and television audiences. ${ }^{19}$

On September 15, 1997, the Internet Advertising Bureau (IAB) released its own document, entitled Metrics \& Methodology. ${ }^{20}$ The thirty-eight-member Media Measurement Task Force that produced this document included representation from the owners of such immensely popular sites as Yahoo and Playboy, as well as from ad buyers such as Microsoft. Although both sets of guidelines are tailored to the advertising industry, librarians can use them as models for standards appropriate to the needs of their profession.

\section{Recommendations for Developing a Benchmarking Program}

A Web site benchmarking program for academic libraries could be designed and implemented either informally among a few institutions or formally among many libraries. Based on experience in collecting and comparing usage data from fourteen test institutions, this article proposes some voluntary guidelines and a common set of metrics for the estimation of library Web site audiences so as to make future cross-site comparisons a possibility. 


\section{Determination of Web Peers}

Whether seeking to establish an informal benchmarking network of a few libraries or to identify which libraries within a formal reporting structure to benchmark against, identification of the library's Web peer group is an important first step toward obtaining and using Web server usage statistics profitably. One of the most interesting conclusions from the authors' study is that libraries cannot determine their Web peer group simply by comparing numerical usage statistics. There are important nonnumeric characteristics to consider as well, and these defining characteristics should be reported along with the numerical usage statistics in benchmarking programs. Finding a Web peer group is a three-step process:

Step 1. Identify the starting pool. The first step is to identify a starting pool of those institutions or individual branch libraries whose character or activities are of interest. The pool could contain the library's ARL peers, other institutions it usually benchmarks against because of similarities in student population or academic programs, institutions in the collection development consortia, or institutions with particularly noteworthy Web sites the library admires and wants to emulate.

Surprisingly, a library's ARL peer is not necessarily its Web peer. Admittedly, a larger sample might prove otherwise, but among the fourteen libraries in this study, an institution's overall ARL ranking bore no statistical relationship to the number of hits to its Web site or to the number of bytes transferred. In the study group of ARL institutions, Web site hits were not statistically correlated with circulation statistics, reference queries, number of full-time students, number of teaching faculty, or dollar amount of research grants received by the institution. In addition, age of the Web site showed no correlation to the number of hits: some young sites received more hits than older sites. Apparently, Web site character and quality are more influential in affecting usage than are the characteristics of the parent institution. By all means, ARL peers should be included in the starting pool because the library should benchmark itself against institutions it cares about; however, the starting pool should not be limited exclusively to the library's peers in the traditional sense.

Step 2. Narrow the list after site examination. The second step is to find Web peers from among those in the starting pool by examining each Web site. In the study, the authors were tempted to skip this step and merely rank their site against those with similar numbers of page requests because they had the luxury of having data from so many institutions in hand. When the authors did this, institution A (see table 1) appeared to be the only candidate to consider partnering with for future exchanges of benchmarking information. However, after examining the Web sites more carefully, it became clear that institution E was actually the closest peer because of its similarity in subject scope and design philosophy, site architecture, and target audience. These site characteristics are the important nonnumerical data elements that benchmarking programs should also collect. Figure 4 illustrates how the essential nonnumeric characteristics of each participant, as well as the numeric data, might be reported, whether the reporting form is paper or electronic. In locating one's Web peer, the ability to sort on these nonnumeric characteristics to narrow the starting pool becomes important.

Subject Scope and Philosophy. Obviously, a good subject match is important among peers. The information-seeking behavior of individuals, the availability of Web data sources, and the suitability of subject-specific data to presentation in a Web environment do differ somewhat by discipline. Equally important, however, is how the site is designed to present the various subjects to the visitor.

It bears repeating that in the study the authors attempted to ignore the structure 


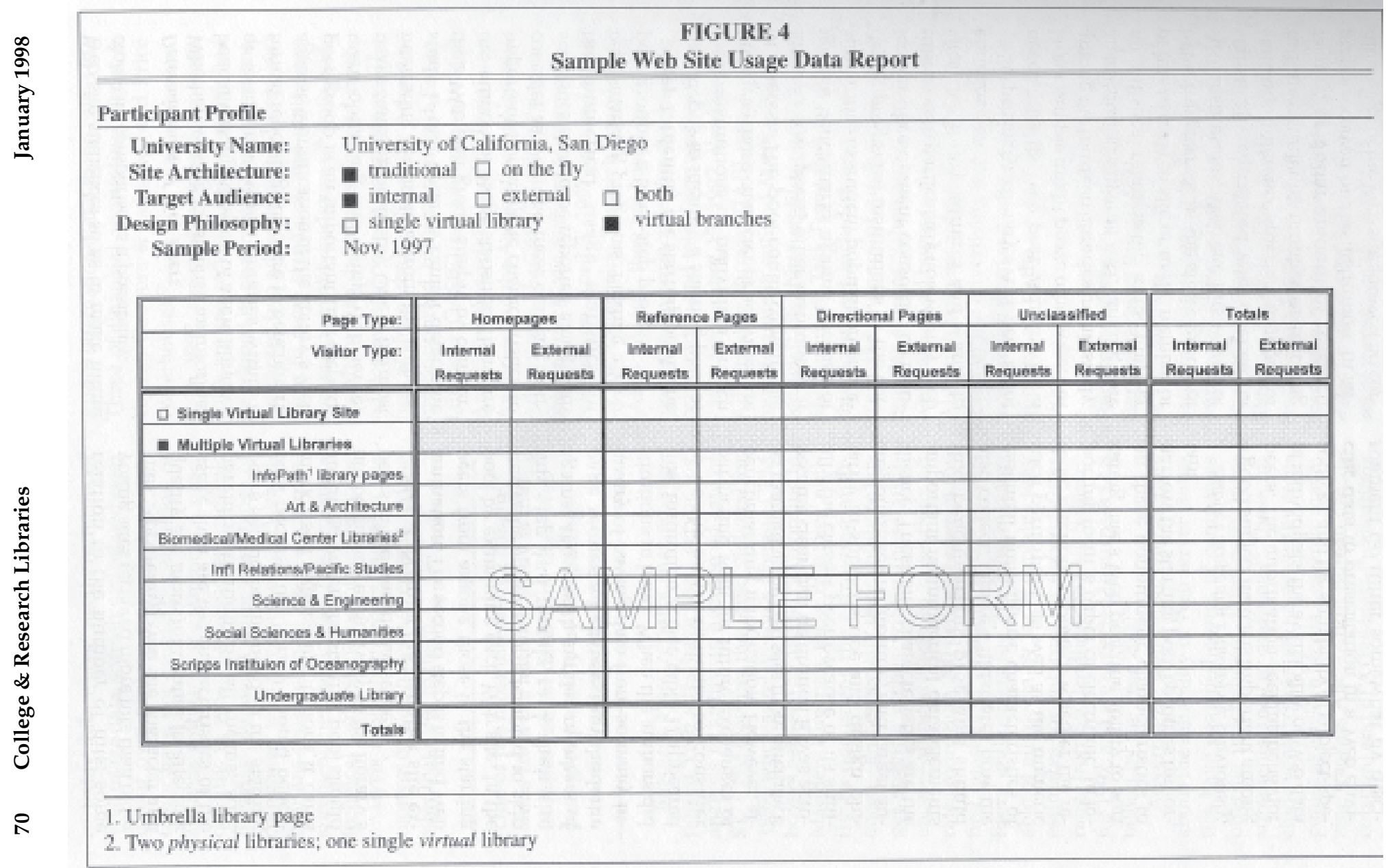


of the Web sites sampled, with unsatisfactory results. Their attempts to compile statistics from multiple sci/tech library sites in order to construct at each institution a virtual counterpart to their own library's Web site (see figure 3) was timeconsuming and awkward, and left lingering doubts about equality because the structure of any site influences the visitor's path (and thus page request counts) so greatly. Combining separate virtual branch library sites statistically after the fact is not the same as presenting a combined, unified site to users and then measuring the resulting traffic.

The authors contend that a visitor to a site designed as a single virtual library, containing links to all subject areas, has a different experience than one who comes to a site that presents itself as several virtual branches, each serving different disciplines. This virtual structure will affect hit counts in much the same manner as physical gate counts are affected by the existence of physical branch libraries. Single virtual "central" libraries and separate virtual branches are each valid design choices, but because the choice may affect page request counts, it is wise to select peers whose design is a match. In figure 4, each participant's design philosophy is categorized as being either a single virtual library site or a site with multiple virtual branch libraries.

In cases of differing numbers of virtual branch libraries, it may be useful to consider constructing a peer group of individual subject pages rather than whole Web sites. Thus, an engineering (or patents, or chemistry) subject page, for example, could be compared to other libraries' engineering (or patents, or chemistry) page rather than to their whole engineering library Web site. (See table 1 for engineering page request totals in the study group.)

Design factors other than the presence or absence of virtual branches also can affect page request counts. In this study, the authors considered using edited byte counts (site totals minus bytes for multi- media files) in relation to hit counts as a numeric indicator of the size and richness of libraries' HTML documents (see table 2). However, subjective assessments, based on visits to each Web site, were found to be more informative for peer choices. The presence or absence of link annotations, the number of useful links on each page, the presence or absence of a "home" button on every page, and the number of layers or "clicks" separating common starting and ending points also affect hit counts. ${ }^{21}$ The number of additional design factors to consider in choosing a peer group is a judgment call.

Site Architecture. In addition to these design variables, even more fundamental differences can exist in a site's architecture or technical implementation. Traditionally, Web sites are collections of HTML documents containing links and text. These HTML pages are "handcrafted," constructed individually by subject specialists, and sit ready and waiting for a visitor to browse to find the links and information he or she needs. However, an alternative model for constructing Web sites has emerged and is gaining support as the best way to scale up or "automate" the construction of Web pages. In this new model, the site is actually a database of individual links with their associated annotations, and the HTML page the visitor sees is created mechanically on the fly from this database of links and customized to match the visitor's typed-in query. In the new model, the vocabulary used greatly affects the content of the page viewed. The two models could produce either very similar or potentially very different page structures, but at the very least the keyword search entry point probably would inspire vastly different browsing and query behavior from visitors. Usage statistics based on page requests cannot honestly be compared between sites that offer visitors such different informationseeking experiences. (In the study, only institution $C$ used this database or a machine-generated, on-the-fly model for 
page generation.) In figure 4 , the site architecture is noted in the participant's profile.

Target Audience. In narrowing the list of potential peers, the library also should look for a match in the site's target audience. For benchmarking purposes in academic libraries, page requests for internal and external users should be reported separately (see figure 1). Some library sites are designed and marketed to be a resource to the entire world. (In the study group, institutions A and C were of this type.) These sites have unique digitized holdings, offer unique programs, or in some other way significantly add to the value of their sites with the goal of serving the needs of users beyond their home institutions. The sites are consciously

\section{Some library sites are designed and marketed to be a resource to the entire world.}

marketed to external users. Because the UCSD S\&E Library's target audience is the faculty, staff, and students on campus, institutions $\mathrm{A}$ and $\mathrm{C}$ would fall outside its peer group.

Categorizing Web sites in the reporting structure according to design philosophy (single virtual library versus multiple virtual branches), site architecture (traditional handcrafted versus machine-generated, on the fly), and target audience (internal, external, or both) will give Web server page request counts more meaningful context and aid in peer identification. These three defining characteristics could easily be identified in a participant profile section of the Web site usage data report (see figure 4).

Finally, in examining the sites of each potential peer, the library also should look for whatever it values and admires most in a library Web site (e.g., sites with no stale pages, sites that consistently exhibit proactive and innovative uses of technology to improve service to their users). Its peer group should contain some exem- plary sites that are inspiring.

Step 3. Evaluate following a trial run. Once the library has selected a peer group from the initial pool, the third and final step is to do a trial run and evaluate the usefulness of the match. Either internal, external, or total page accesses should be examined, as appropriate for the library's own site's goals. If the page access counts for some sites in the library's group are substantially lower, it is debatable how useful continued comparison with those sites will be. The library may want to consider dropping them from its pool if the time and effort necessary to obtain their data is high. (Of course, because the Web is always changing, the low-traffic sites may bear reexamination in the near future.) If a noteworthy site similar in architecture and purpose has page access counts that are substantially higher, it might be kept as a model to aim for. Also, it may be useful to consider constructing a peer group of selected subject pages rather than whole institutions if that would help the library's development goals.

\section{Most Useful Statistics for Benchmarking Purposes}

Statistical analysis of $\log$ files results in a great deal of data that are fascinating to a Web site's creators but of negligible interest to their peer institutions. This article has already discussed the negligible value of cross-site comparisons of byte transmissions in the context of peer selection; the authors further note that both sets of advertising industry guidelines examined omit mention of bytes entirely. What librarians_-and advertisers-really want to know is this: How many unique individuals are using the resources on a particular Web site, and how does that number measure up to other, similar sites? Average and actual incidence of repeat visits also would be an indicator of sites' ability to maintain an audience.

Advertisers are hot on the pursuit of this "unique visitor" data, which Kirsner 
calls "the holy grail of site measurement." 22 Unfortunately, most of the existing methods of visitor identification (e.g., sending cookie files or tracers, ${ }^{23}$ or consulting IP address tables) identify individual computers-a futile strategy in campus computer lab and shared library workstation environments. Demanding self-identification for each session via surveys or passwords is intrusive upon the user and programming-intensive for the library.

Therefore, Web audiences must be estimated based on the number of "hits" (requests for individual files) made upon the server. Selecting which of these hits to count is essential for objective comparisons. For example, in the case of a library Web page that makes liberal use of decorative graphics (e.g., library logo, backgrounds, bullets), a single visit registers several hits on the server-one for the HTML file and one for each of the nontext elements, which are treated as individual files. This phenomenon can inflate a site's aggregate hit count significantly. The authors recommend reporting "page requests" rather than "hits" as defined by the IAB. For nonframed pages, a page request is defined as "An opportunity for an HTML document to be displayed within a browser window, which may contain text, images, media objects (i.e., Java, Shockwave, Real Audio) or other online elements." ${ }^{24}$ Thus, multimedia files are eliminated from the log before analysis. Table 1 reports page requests rather than hits under this definition.

Participants in benchmarking programs should preprogram their analysis software to ignore hits resulting from unsuccessful or rerouted requests. In addition, agreement should be reached on the treatment of hits from content-rich multimedia files and OPAC interfaces.

"Multimedia files" is a class that spans from 120-byte GIF images of bullets to $100 \mathrm{Mb}+$ audiovideo extravaganzas. At the high end are data-rich files such as those presented by art, music, architec- ture, and map libraries. Because multimedia hit count comparisons would be worthwhile only between items of the same data type, these resources would be better benchmarked in a separate program designed for that purpose.

Although Web versions of OPACs do contribute to institutions' Web presence, the navigational patterns that characterize their usage are significantly different from other library Web pages. For that reason, Web OPAC usage data also should be benchmarked as part of a separate program, if at all.

\section{Level of Detail at Which Page Requests Should Be Reported}

Frequency. Analysis of the authors' own site's usage over time reveals that traffic varies greatly depending on whether an academic term is in session. To facilitate comparisons between quarter-system and semester institutions, institutions should report their statistics on a monthly basis.

Another argument for reporting Web server traffic on a monthly basis, rather than by academic term or year, is the great speed at which Web functionality develops. Libraries that seek to be dynamic reorganize their Web sites frequently as they create new resources and employ new functions. Monthly reports are more likely to distinguish the effects of these newly added (or newly deleted) files on overall usage patterns.

As noted previously, the CLF format contains a wealth of information, and analysis software can be configured to present this information at varying levels of detail. This gives participants in statistical exchanges a great deal of flexibility. However, some options provide more useful benchmarking indicators than others. In the study, the authors evaluated these various measures to determine the ideal format for statistical reports among peers.

Page requests for selected pages. The authors investigated whether evaluation of page request counts for the ten most 


\section{FIGURE 5 Types of Webpages}

Homepage: The top-level document relating to a virtual library site. All the other pages constituting that site are usually accessible by following links from the homepage.

Directional pages: Those pages that give directions, answer short questions, or state policy, e.g., pages that list branch libraries, give overviews of collections and services, list building hours, library mission statements, circulation policies.

Reference pages: Those pages that provide substantive data, e.g., detailed guides to using the collection or specific databases, guides to Internet resources, data sets.

Combination pages: Pages that combine both directional and reference type data, such as library newsletters, should be tallied according to the type of information that predominates. For instance, if more than half of the content of the newsletter is considered directional (e.g., how to get a library card), count it as "directional," but if more than half is devoted to substantive discussions (e.g., providing instruction in the use of new databases), the entire newsletter page should be counted as "reference."

heavily used Web pages at each library Web site would prove more convenient or more telling than evaluation of total page requests. The study did not reveal significant statistical differences between these two measurements (see table 1). Analyzing the top ten pages would provide a quick and dirty way to determine overall "rankings" in terms of which institutions' Web sites receive the most traffic. However, these rankings alone are of negligible value for benchmarking purposes because they do not allow one to evaluate whether another institution's Web site is truly comparable to one's own in terms of design philosophy, level of development, or intended audience. The authors do not recommend reporting page requests for subsets of pages based on numerical thresholds (i.e., top ten most-used pages).

Comparisons based on home page requests alone also are unsatisfactory for benchmarking purposes. The highly nonlinear nature of the Web, the ability to bookmark interior pages, and the fact that search engines usually send visitors directly to interior pages makes counting the home pages alone inadvisable. However, requests for home pages, reference pages, and directional pages may be useful to report separately, as long as all pages intended for public use are reported in site totals.

Just as reference queries are tallied separately from directional queries at most reference desks, requests for Web pages that present reference-type data and those that present directional or policy information should be tallied separately (see figure 4). These two categories of Web pages function differently and represent vastly different levels of intellectual effort to create and maintain them. Simple definitions could be established for determining whether a particular Web page should be considered primarily "reference" or primarily "directional" (see figure 5). Because library home pages usually incorporate both these elements, they would be counted in a third category.

Prior to the first data collection, each page at a Web site would be classified by type. A simple script would separate the pages for analysis every time thereafter (metadata tags might prove useful here). This classification requires some initial setup time but would greatly improve benchmarking quality.

Design philosophy. Page request reports should reflect whether a Web site is designed on a central or branch model because this affects the pattern of traffic flow. Web sites organized on a collaborative model, in which the visitor's experience is of a single virtual library covering all disciplines, should report Web 
server usage for their site as a whole. In contrast, Web sites whose major organizational divisions give users the sense of visiting separate virtual libraries should report subtotals that reflect this organization (see figure 4).

Primary versus secondary clientele. Furthermore, hit counts for each of these categories should be reported by visitor origin (internal, external, or unresolved) (see figure 1). If the site is primarily designed to serve the needs of local users and little or no effort is expended on external promotion, the library's benchmarking efforts should focus on comparing its internal hit count to the internal hit count of other institutions that share its emphasis on the local user.

Because the incoming IP address of each visitor is recorded in the access log (see figure 2), the analysis software can easily check the IP address against a list of known IP addresses to tally requests originating from machines on campus separately from those originating outside the campus. This is a standard feature of the wwwstat package.

Comparing Web site data across institutions requires more attention to detail than is currently the case with other types of data reported to ARL. Preserving an appropriate level of detail for equitable comparisons between sites makes Web usage data more complex than most other commonly exchanged statistics. However, once correctly programmed, the data collection is completely automatic and devoid of human error, unlike most other statistics reported to ARL.

\section{Implementation and Administration Issues}

The authors of this article strongly favor establishment of a formal reporting structure for comparing Web server statistics across academic libraries. Benchmarking efforts would be greatly facilitated by central collection and distribution of these data, according to preestablished standards (patterned after the IAB model) defining comparable metrics for estima- tion of library Web site audiences. Such an infrastructure would provide a larger pool of potential peers for selection and would eliminate the need to forge piecemeal partnerships with other institutions in order to obtain their data.

The Need to Inspire Commitment. In January 1996, the authors sent a questionnaire to the fourteen participating university libraries, plus three other ARL institutions, which asked both Web content providers and Web site administrators a number of questions concerning how their Web site statistics were being used. The survey data indicated that the practical applications of Web server log file analysis were sorely underutilized in the sample population. Although eleven of the seventeen technical Web site administrators surveyed (almost 65\%) said they use Web server analysis software to interpret their log files, only four respondents (under $24 \%$ ) claimed that the content providers of their sci/tech libraries' Web sites examined their usage statistics on a regular basis. Eight respondents (just over $47 \%$ ) reported that their sci/tech Web page creators either had never requested to see usage statistics for their Web sites or were still waiting for their technical administrators to make them

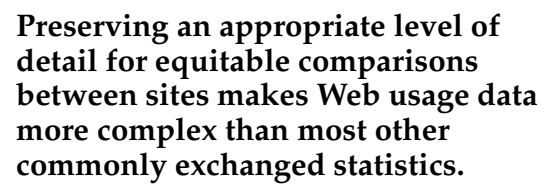

available. Four others said that content authors requested these data only "occasionally"-defined as less than once per academic semester or quarter. (One respondent said that monthly statistics could be found on an internal page at any time but did not indicate whether content authors were taking advantage of this.) Fourteen of the seventeen responding institutions (just over 82\%) indicated that, as of the time of the survey, usage statistics had never affected decisions as to how 
staff hours should be allocated among the various aspects of their Web sites.

A pessimist, upon observing these libraries' failure to capitalize on their own Web server data, would question whether these same libraries would be inclined to support a more ambitious, multicampus undertaking. However, the authors are optimistic that the visibility of such a benchmarking opportunity would capture the attention of these libraries' administrators; with increased priority given to Web server statistics would come increased awareness of-and subsequent productive use of-the wealth of information contained in Web server log files. The authors also note that several of the Web sites in the sample were only a few months old in January 1996; when surveyed, their creators' time was monopolized by basic development, but as their Web sites mature, these individuals become more receptive to the idea of using sophisticated management aids.

Possible Roles for ARL. ARL's Office of Statistics seems a logical choice for coordinating a voluntary reporting structure among ARL members. Its expertise would prove a great asset in selecting a uniform software package or commercial service to be used by all participants. To keep pace with the rapid changes in Web site technology, this office also could assist by identifying and evaluating new analysis tools. In addition, its innovative and exemplary Web page, ${ }^{25}$ where customized ARL statistical reports are already available, would be a natural home for the distribution of Web usage data.

Identification of the ideal method for analyzing participants' Web server data would be one of the most important roles of the Office of Statistics. It is unlikely that the office would want to allocate the necessary server space to collect, analyze, and archive institutions' raw log files each month, so participants would need to either analyze their own data using a uniform software tool, configured uniformly, or use the same commercial service.
The libraries in this study that were regularly analyzing their own institutions' access logs either wrote their own programs to do so or used one of the serviceable shareware or freely available software packages that have been available for a few years now, such as wwwstat. Due to the easy availability of low-cost software, none of the study participants chose to contract with a commercial service to have their Web server log file analysis performed for them. ${ }^{26} \mathrm{Com}-$ mercial analysis can be done on-site by purchasing software to run at the library's end, thus allowing a high degree of interactivity and the ability to generate customized reports at any time. Or, commercial analysis can be done off-site. Offsite analysis saves time and system resources but gives less control over the format and frequency of reports. Again, the Office of Statistics would be uniquely qualified to evaluate these options and to help select the best analysis method for program participants.

Technical support staff from the Office of Statistics might direct a network of volunteers from the technical Web support staff at various ARL institutions who understand how to configure the analysis software according to established standards. These volunteers would be available to help library Web server administrators with both the initial setup and ongoing adaptations to the configuration as their Web sites change and grow. Ideally, each institution would undergo an annual audit to confirm that the software is configured in a standardized way.

Because the Web is evolving so quickly, any large-scale benchmarking scheme will undoubtedly need periodic revision. Nevertheless, the Web itself and the software for analyzing Web server statistics are mature enough today to begin a benchmarking program. The level of effort being poured into library Web sites and the degree of importance that Web sites have to library users justify the effort required to mount such a program. 


\section{Summary of Recommendations}

The authors strongly favor establishment of a voluntary reporting structure for comparing Web server statistics across academic libraries. Seven recommendations for developing a centralized voluntary benchmarking program are proposed below. The ARL Office of Statistics is well suited to coordinate such a program, and would provide a significant service to its members by doing so.

1. Selecting peers for Web site benchmarking is a three-step process:

Step 1. Identify a starting pool of institutions whose character or activities interest the library.

Step 2. Narrow the list by examining each Web site, looking for matches in subject scope and design philosophy, site architecture, target audience, and other desirable characteristics.

Step 3. Perform a trial run to evaluate the usefulness of the match.

2. Page requests, as defined by the IAB, are the most practical basis for multisite comparisons. Purely decorative or directional multimedia files (pictures, bullets, icons, etc.) and error messages should be eliminated from reported totals.

3. Hits from data-rich multimedia files, Web OPACs, and commercial products (e.g., electronic journals) would be excluded from this benchmarking program.

4. Page requests for each institution should be reported on a monthly basis, according to the various categories of component pages:

- All library Web pages at an institution should be considered, not just home pages or the top ten pages from each branch.

- Traffic subtotals should be reported in terms of Web sites' major organizational components (which frame how visitors navigate the site); these subtotals may not always parallel the host libraries' physi$\mathrm{cal} /$ administrative structure or the struc- ture of the computers serving the data.

- "Reference"-type Web pages should be totaled separately from pages that are merely "directional."

- For each of these categories, page requests should be reported by visitor origin (internal, external, unresolved).

5. Page request comparisons are more meaningful when institutions' usage data are sorted according to shared site characteristics:

- Design philosophy: Collaborative approach versus branch by branch

- Site architecture: Handcrafted versus on the fly

- Target audience: External promotion versus no external promotion

6. A formal reporting structure for comparing Web server statistics across institutions would greatly facilitate benchmarking of usage data by:

- Motivating more institutions to participate, thus providing a larger pool of potential peers

- Eliminating the need to forge piecemeal partnerships with other institutions in order to obtain their data

7. The ARL Office of Statistics should provide centralized coordination and assistance for exchanging Web server usage data, including:

- Ensuring consistency through establishment of voluntary standards for defining comparable metrics for estimating academic library audiences

- Determining the most effective, uniform means for participants to analyze their data, through selection of a software package or an analytical service to be used by all

- Serving as the centralized collection point for institutions' reported data and by overseeing periodic audits

- Distributing the reported data through the ARL Office of Statistics Web page

- Providing a yearly evaluation of the program's effectiveness

This work was supported by a grant from the Research Grants for Librarians Program, 
awarded by the Librarians Association of the University of California, San Diego Division. The authors are grateful for the participation of those libraries that shared their data. They also would like to thank Susan Starr, Jim Jacobs, and Suzanne Wakerly for their many helpful comments on early drafts of this article.

\section{Notes}

1. The wwwstat software, written by Roy Fielding, is available from the University of California-Irvine Department of Information and Computer Science at http:/ / www.ics.uci.edu/pub/ websoft/wwwstat (Nov. 1996).

2. "How Can I Keep Statistics about My Web Server?" at http://www.boutell.com/faq/ stats.htm (Apr. 1996) is the relevant section of Thomas Boutell, WWW FAQ: Frequently-Asked Questions (Answered, of Course!). The comp.infosystems.www USENET newsgroup has since been divided into fifteen separate newsgroups, accessible via http://www.boutell.com/faq/ ngroups.htm (Apr. 1996).

3. Materials from the Web4Lib Electronic Discussion, including a searchable archive and The Library Web Manager's Reference Center, may be accessed from http://sunsite.berkeley.edu/ Web4Lib/ (Sept. 1997).

4. The most helpful of these were: Steven J. Vaughn-Nichols, "Caching Could Stall Internet Commerce," Byte 20, no. 6 (June 1995): 40; Julie Chao, "Tallies of Web-Site Browsers Often Deceive," Wall Street Journal, June 21, 1995, 1(B); Ellis Booker, "Labor Day in Tuktoyaktuk?" Computerworld 29 (July 10, 1995): 58; Matthew Cutler and Devra Hall, "Sizing 'Em Up," Internet World 6, no. 8 (Aug. 1995): 22-24; Stephen Howard, "Have We Got a Hit?" MacWEEK 9 (Sept. 11, 1995): 3; Wayne Rash Jr., "Demand Grows for Commercial Accountability on the Internet," CommunicationsWeek (Nov. 6, 1995): 86; John Evan Frook, "Web-Hit Audit System Called into Question," CommunicationsWeek (Dec. 18, 1995): 1; Jeff Ubois, "The Art of the Audit," Internet World 6, no. 12 (Dec. 1995): 62-74; Niel Robertson, "Stalking the Elusive Usage Data," Internet World 7, no. 4 (Apr. 1996): 28-31.

5. Rick Stout, Web Site Stats: Tracking Hits and Analyzing Traffic (Berkeley, Calif: Osborne McGraw-Hill, 1997); Robert W. Buchanan Jr. and Charles Lukaszewski, Measuring the Impact of Your Web Site (New York: John Wiley \& Sons, 1997).

6. The most recent of these are Mitch Wagner's buyers guide for various software tools in “Tracking Web Users Is Getting Easier," Computerworld 31 (Mar. 3, 1997): 59, 63; and Linda Rich's review of several Web measurement services in "Count Them In," Mediaweek 7 (Feb. 3, 1997): IQ24-IQ29. Consult http://www.yahoo.com/Computers_and_Internet/Software/Internet/ World_Wide_Web/Servers/Log_Analysis_Tools/ for additional freeware, shareware, and commercial analysis products.

7. Tova Stabin and Irene Owen, "Gathering Usage Statistics at an Environmental Health Library Web Site," Computers in Libraries 17, no. 3 (Mar. 1997): 30-37.

8. Norman Friesen, "Monitoring the Use of World Wide Web Pages," available at http:// www.ualberta.ca/ nfriesen/597/.index.html (Jan. 10, 1996).

9. Laurel A. Clyde, "The Library as Information Provider: The Home Page," Electronic Library 14, no. 6 (Dec. 1996): 549-558. This is a survey of many libraries but does not examine usage data.

10. Linda Himelstein, Ellen Neuborne, and Paul M. Eng, "Web Ads Start to Click," Business Week (Oct. 6, 1997): 128-38. 71.

11. Matthew Kinsman, “Online Advertising: The Basics," Catalog Age 14 (Sept. 1, 1997): 70-

12. Michael Krantz, "The Medium Is the Measure," Mediaweek 5 (Sept. 25, 1995): IQ20-IQ24.

13. Veronis, Suhler \& Associates' estimate, as reported in Catherine P. Taylor, "Everything Catches in the Net," Adweek (Eastern Ed.) 38 (Sept. 8, 1997): MO32.

14. Jupiter Communications Inc.'s projection, as reported in Himelstein, Neuborne, and Eng, "Web Ads Start to Click," 128-38.

15. Purrester Research, as reported in Mark Halper, "So, Does Your Web Site Pay?" Forbes, ASAP Supplement (Aug. 25, 1997): 117-18.

16. An excellent recent overview, from the perspective of newspapers that sell ad space on their Web sites, is Scott Kirsner, "Web of Confusion," American Journalism Review 19, no. 6 (July/ Aug. 1997): 34-39. See also Paul Demery, "Keeping a Reliable Score of 'Hits,'” Practical Accountant 30 (Mar. 1997): 16; Jodi B. Cohen, "Web Audits: A Complex Art," Editor \& Publisher 130 (Feb. 
3, 1997): 24I-26I.

17. Damon Darlin, "Ratings Game," Forbes 158 (Dec. 2, 1996): 226; Cris Beam, "ABC and BPA Audit the Body Electric," Folio: The Magazine for Magazine Management 25 (Oct. 15, 1996): 30-32; Jane Hodges, "BPA Questions Int'l Audit Standards," Advertising Age 68 (Feb. 3, 1997): 56; Himelstein, Neuborne, and Eng, "Web Ads Start to Click," 134.

18. Consult http://www.yahoo.com/Computers_and_Internet/Software/Internet/ World_Wide_Web/Servers/Log_Analysis_Tools/Titles for an extensive list of Web server log analysis software and services.

19. Coalition for Advertising-Supported Information and Entertainment, CASIE Guiding Principles of Interactive Media Audience Measurements, available at http:/ / www.commercepark.com/ AAAA/casie/gp/guiding_principles.html (Apr. 3, 1997).

20. Internet Advertising Bureau Media Measurement Task Force, Metrics and Methodology, available at http://www.iab.net/advertise/metricsource.html (Sept. 15, 1997).

21. Kirsner, "Web of Confusion," 36-39.

22. Ibid., 36.

23. Neil Randall, "The New Cookie Monster," PC Magazine 16 (Apr. 22, 1997): 211-14; Stephen H. Wildstrom, "Privacy and the 'Cookie' Monster," Business Week no. 3506 (Dec. 16, 1996): 22.

24. IAB, Metrics and Methodology.

25. Association of Research Libraries, ARL Statistics and Information, available at http:// www.arl.org/stats/statistics/stat.html (Apr. 1997).

26. See note 6 above for reviews of such software and services. 